\title{
EFFECTS OF JUICE AND SEED EXTRACT OF POMEGRANATE ON OXIDATIVE STRESS, INFLAMMATION, AND PHOSPHORYLATION OF ERK1/2 IN PARAQUAT-INDUCED ACUTE LUNG INJURY IN MICE
}

\author{
Samah M. Fathy ${ }^{*}$; Heba A. El-Dash; Noha I. Said \\ Zoology Department, Faculty of Science, Fayoum University, Fayoum, Egypt
}

\begin{tabular}{l} 
Article History: \\
Received: 27 December 2020 \\
Accepted: 20 January 2021 \\
Published Online: \\
\hline 28 January 2021 \\
Keywords: \\
Inflammation \\
Lung injury \\
Paraquat \\
pERK1/2 \\
Pomegranate \\
*Correspondence: \\
Samah Fathy \\
Zoology Department \\
Faculty of Science \\
Fayoum University \\
Fayoum, Egypt \\
E-mail: \\
smm01 @ fayoum.edu.eg
\end{tabular}

Article History:

Received: 27 December 2020

Accepted: 20 January 202

Published Online:

Keywords:

Inflammation

Lung injury

Paraquat

pERK1/2

*Correspondence:

Samah Fathy

Fayoum, Egypt

smm01@fayoum.edu.eg

\begin{abstract}
Pulmonary fibrosis is considered the most distinctive feature of paraquat (PQ) poisoning. Inflammation and oxidative stress play crucial roles in the pathogenesis of PQ-induced pulmonary fibrosis. The current study was designed to assess the efficacy of pomegranate juice (PJ) and pomegranate seed extract (PSE) supplementation against PQ-induced pulmonary fibrosis in a mouse model. Male mice (Mus musculus) were randomly divided into four experimental groups $(\mathrm{n}=8)$ ). Group 1 (control group) received $0.9 \%$ saline only; group 2 received a single intraperitoneal injection of PQ (30 mg/kg); and groups 3 and 4 were daily treated with PJ (5 mL, 1:40 dilution) or PSE (500 $\mathrm{mg} / \mathrm{kg}$ body weight, suspended in distilled water), respectively, by gavage one week before the PQ injection, then continued for 3 weeks. PQ increased significantly the levels of hydroxproline, reduced nicotinamide adenine dinucleotide phosphate (NADPH) oxidase 4 (NOX4), nitric oxide (NO), malondialdehyde (MDA), and extracellular signal-regulated kinase $1 / 2$ (ERK1/2) in the lung tissue compared with the control group. Furthermore, the levels of interleukins (IL-6 and IL-17), transforming growth factor (TGF)- $\beta 1$, and CC chemokine ligand 2 (CCL2) elevated significantly in the lung tissue due to PQ injection. Administration of PJ or PSE alleviated markedly the biochemical lung alterations caused by PQ injection. Additionally, PJ and PSE supplementation decreased the levels of IL-6, IL-17, TGF- $\beta 1$, and CCL2, as well as reduced significantly the phosphorylated (p)-ERK1/2, in PQ-treated mice. In conclusion, administration of PJ and PSE attenuated effectively PQ-induced lung injury in mice by modulating inflammation, oxidative stress, and fibrosis.
\end{abstract}

\section{INTRODUCTION}

Paraquat (PQ; 1, 10- dimethyl-4, 40-bipyridinium dichloride) is an effective herbicide, which is used globally for weed control to enhance crop yields. The toxicity of PQ has been reported on various organs, including the lung, heart, liver, kidney, and central nervous system ${ }^{[1,2]}$. The primary target organ in PQ poisoning is the lung causing lethal pulmonary fibrosis. Pulmonary fibrosis due to PQ ingestion has resulted in the death of a large number of 
humans throughout the world especially in developing countries ${ }^{[2]}$. For this reason, PQ-induced lung damage in animals has been used as an experimental model of lung fibrosis ${ }^{[3]}$. The pneumotoxic effect of $\mathrm{PQ}$ is due to its selective accumulation in the lung due to active uptake system, followed by sustained cyclic redox reactions that lead to oxidative stress-related cell death and inflammation ${ }^{[4]}$. Accumulation of PQ molecules begins immediately after ingestion and lasts from two to four weeks ${ }^{[5]}$; low doses of PQ (e.g., $5 \mathrm{mg} / \mathrm{kg}$ body weight) were reported to induce chronic lung injury in laboratory animals ${ }^{[6]}$.

The development of pulmonary fibrosis by PQ takes place in two distinct phases. The first phase is a destructive phase that takes place within 1-3 days after poisoning, during it the alveolar type I and II epithelial cells are destroyed ${ }^{[7]}$. The second phase is the proliferative phase that occurs several days after PQ ingestion and characterized by alveolitis, lung edema, infiltration of inflammatory cells into the interstitial and alveolar spaces, proliferation of the bronchial epithelium, and damage of the alveolar epithelial cells followed by extensive lung fibrosis that finally leads to death due to respiratory failure ${ }^{[7]}$. The mechanism for PQ toxicity was linked to PQ redox potential by undergoing redox cycling, which results in the generation of reactive oxygen species (ROS) and the depletion of reduced nicotinamide adenine dinucleotide phosphate $(\mathrm{NADPH})^{[8,9]}$. Moreover, the production of ROS induces deleterious impacts on the membrane lipids leading to lipid peroxidation and lung tissue damage ${ }^{[10]}$.

In addition to oxidative stress, inflammation has been demonstrated as another mechanism in the development of lung injury ${ }^{[11,12]}$. It has been reported that lung cells in case of oxidative stress generate inflammatory cytokines and chemokines such as transforming growth factor- $\beta 1$ (TGF- $\beta 1$ ) and interleukins (ILs) including IL-1 and IL-6 that lead to the proliferation and differentiation of fibroblasts in the lung tissue and subsequent development of pulmonary fibrosis ${ }^{[13]}$. The CC chemokine ligand 2 (CCL2) is also recognized as monocyte chemotactic protein-1. It is one of the $\mathrm{CC}$ chemokine family ${ }^{[13]}$ that plays a role in lung inflammation by stimulating the migration of monocytes and lymphocytes to the sites of inflammation. In addition, CCL2 stimulates the release of IL-6 from synovial fibroblasts ${ }^{[14]}$. Several pieces of evidences from both animal and human studies suggest that CCL2 may contribute to the development of fibrosis in multiple organs ${ }^{[13]}$.

The extracellular signal-regulated kinase $1 / 2$ (ERK1/2) belongs to the non-Smad pathways for TGF- $\beta$ signaling ${ }^{[15]}$. It has been reported that CCL2/TGF- $\beta 1$-mediated pulmonary fibrosis was related to the induced ERK1/2 phosphorylation ${ }^{[13,15]}$. It has been also shown that ERK1 exerts a crucial role in the differentiation and development of $\mathrm{T}$ helper- 2 cells in an experimental model of asthma ${ }^{[16]}$.

Based on the fact that PQ is a strong redox/inflammatory agent and contributes to the formation of ROS, attempts for prevention of $\mathrm{PQ}$ induced lung toxicity have been therefore directed to explore strategies that may prevent the generation of ROS and suppressing the expression of fibrosisrelated cytokines and chemokines. Punica granatum L. (Punicaceae), generally known as pomegranate, has recently received considerable attention for its antioxidant ${ }^{[17]}$ and anti-inflammatory properties ${ }^{[18]}$. Various parts of pomegranate fruit including peel, juice, and seeds exert high antioxidant activity due to their high contents of phenolic ${ }^{[19]}$ and flavonoid compounds ${ }^{[20]}$. It has been reported that pomegranate seed extract (PSE) and pomegranate peel extract have protective effects against methotrexateinduced oxidative stress and lipid profile changes in rats ${ }^{[21]}$. Supplementation of pomegranate juice (PJ) to adult rats exposed to hyperoxia for 5 days attenuated ROS production, decreased the expression of inflammatory mediators, and apoptosis ${ }^{[22]}$. Moreover, it has been found that PSE is 
effective in protecting against pulmonary fibrosis and scavenge free radicals in bleomycin-induced lung fibrosis rat model due to its antioxidant properties ${ }^{[18]}$. However, the current study is the first ever to determine the possible antioxidant, antiinflammatory, and antifibrotic effects of PJ and PSE on PQ-induced pulmonary fibrosis in a mouse model.

\section{MATERIAL AND METHODS Chemicals}

PQ dichloride ( $\geq 98 \%$ ) was bought from Sigma (St. Louis, MO, USA). Other used chemicals and reagents were of the highest analytical grade.

\section{Plant material}

Pomegranate (Punica granatum L.) fruits were reaped at Fayoum City (Egypt) in the months of September-October, 2020. The coordinates of the city are latitude $16^{\circ}$ 53' 12.59" $\mathrm{N}$ and longitude: $42^{\circ} 33^{\prime} 23.99^{\prime \prime} \mathrm{E}$ following the degree minutes second system. The plant material was authenticated by a botanist through comparing it with the well-known herbarium specimens found at the Herbarium of Flora Researches Centre, Agriculture Museum Campus, Giza, Egypt.

\section{Preparations of PSE and PJ}

Fresh red pomegranate fruits were washed, manually peeled, the seeds were squeezed and pulsed in juicer-blender. The juice was filtered from the cell debris and kept at $-20^{\circ} \mathrm{C}$. The dried materials of seeds remained after juice preparation was allowed to dry, then ground forming a powder. Thereafter, $500 \mathrm{~g}$ of this powder was extracted in absolute ethanol (1:10 weight/volume) at $25^{\circ} \mathrm{C}$ for 24 hours. The mixture was then filtered by $0.45 \mu \mathrm{m}$ pore size filters. The ethanol was completely evaporated using a rotary vacuum evaporator at $40^{\circ} \mathrm{C}$ and the seed extract was kept at $-20^{\circ} \mathrm{C}$ until use.

\section{Animals}

The current experimental study was performed following the National Health Institute guidelines for Ethical Conduct in the Care and Use of Laboratory Animals. Adult male mice (Mus musculus) weighing 20-24 g (8 weeks old) were purchased from the National Cancer Institute, Egypt. Animals were kept in conventional cages (polycarbonate) under standard conditions of ventilation, temperature $\left(25 \pm 2^{\circ} \mathrm{C}\right)$ and subjected to 12 hours light/dark cycle throughout the entire study. Animals were free to get water ad libitum and food pellet.

\section{Experimental groups and animal dosing}

Animals were divided into four groups (8 mice each) as follows: control group was treated intraperitoneally (i.p.) with $0.9 \%$ saline; PQ group was injected i.p. with a single dose of PQ $(30 \mathrm{mg} / \mathrm{kg})$ as reported by Qian et $a l .{ }^{[23]}$ to induce pulmonary fibrosis; $\mathrm{PQ}+\mathrm{PJ}$ group: animals received $5 \mathrm{~mL}$ of 1:40 dilution of PJ daily by gavage $^{[24]}$ one week before the PQ injection and continued for further 3 weeks; PQ+ PSE group received PSE $(500 \mathrm{mg} / \mathrm{kg} / \mathrm{day}$ suspended in distilled water, daily by gavage $)^{[21]}$ one week before the PQ injection and continued for another 3 weeks ${ }^{[18]}$.

\section{Dissection and sampling}

At the end of the study period, all mice were killed by decapitation under xylazine/ketamine $(10 / 110, \mathrm{mg} / \mathrm{kg})$ anesthesia ${ }^{[25]}$. The lungs were excised, rinsed in ice-cold phosphate buffered saline (PBS, 0.1 mol, pH 7.4), weighed, homogenized in PBS, and sonicated. The homogenates were centrifuged for 5 minutes at $5000 \times g$ at $4^{\circ} \mathrm{C}$ to obtain the supernatant. Protein concentration was measured in the pulmonary supernatant by the Bio-Rad protein assay kits (Hercules, CA, USA) according to the Bradford method ${ }^{[26]}$. The supernatant was used for the evaluation of biochemical and inflammatory parameters in all experimental groups.

\section{Measurement of malondialdehyde (MDA) in the lung tissue}

MDA content in lung tissue was determined based on the formation of thiobarbituric acid reactive substances in the supernatant following the protocol described by Al- 
Fawaeir et $a l .{ }^{[27]}$. The reaction product was measured spectrophotometrically at $532 \mathrm{~nm}$ by using MDA colorimetric/fluorometric assay kit (BioVision Incorporated, CA, USA) against MDA standard solution of tetramethoxypropane.

\section{Determination of nitric oxide (NO) level in the lung tissue}

The level of NO in the lung homogenate was measured according to the Griess method $^{[28]}$ using a colorimetric NO assay kit (Thermo Scientific, LO, UK). Briefly, nitrite is converted to nitrous acid in an acidic medium and the resulting acid then reacts with sulphanilamide. The resulted diazonium is coupled with $\mathrm{N}$-(1-naphthyl)ethylenediamine to form a colored azo dye that was measured at $540 \mathrm{~nm}$.

Evaluation of hydroxyproline, NADPH Oxidase 4 (NOX4), and the inflammatory mediators in the lung tissue

The levels of hydroxyproline, NOX4, IL-6, IL-17, TGF- $\beta 1$, and CCL2 were measured in mice lung tissue by using sandwich enzyme-linked immunosorbent assay kits (Merck Millipore, San Francisco, California, USA) according to the manufacturer's instructions. MR7000 microplate reader (Dynex Technologies Inc., Chantilly, VA, USA) was used to detect the levels of the above-mentioned parameters and the inflammatory mediators at a wavelength of $450 \mathrm{~nm}$.

\section{Western Blotting analysis}

Total (t)-ERK1/2 and phosphorylated (p)ERK1/2 were estimated in the supernatant of the lung tissue by western blotting. Pulmonary supernatant samples $(30 \mu \mathrm{g})$ were loaded and separated by using sodium dodecyl sulfate-polyacrylamide gel electrophoresis followed by transfer onto polyvinylidene difluoride membranes (Millipore Corp., Bedford, MA, USA). After blocking, the membranes were incubated with the specific primary antibodies $(1: 1000$, Thermo Scientific, LO, UK) at $4{ }^{\circ} \mathrm{C}$ overnight. Afterward, incubation with the corresponding secondary antibodies (1:5000, Thermo Scientific, LO, UK) was performed for 1.0 hour at room temperature. Detection reagents for enhanced chemiluminescence (Millipore, CA, USA) were used and the bands were detected using a chemiluminescence system (New Life Science Products, Boston, MA, USA).

\section{Statistical methods}

Statistical analysis of data was performed using GraphPad PRISM (version 6.01; Graph Pad Software, USA). Data were expressed as the mean \pm standard deviation (SD) and analyzed using one-way analysis of variance (ANOVA) followed by Tukey's test. The value of $P<0.05$ among groups was considered statistically significant.

\section{RESULTS}

Effect of PJ and PSE administration on hydroxyproline, NOX4, NO, and MDA levels in the lung tissue of the PQ-treated mice

The levels of hydroxproline, NOX4, NO, and MDA increased significantly $(P<0.001-$ $P<0.0001)$ in the lung of the PQ (alone)treated group compared with the control group (Figure 1). A conceivable reduction was detected in their levels upon treatment with PJ $(P<0.05-P<0.001)$ or PSE $(P<0.01$ $P<0.001)$ compared with PQ (alone)-treated mice (Figure 1).

Effects of PJ and PSE administration on the levels of the pulmonary p-ERK1/2 and t-ERK1/2 of the PQ-treated mice

The current study demonstrated that PQ injection increased significantly the lung $\mathrm{t}-$ ERK1/2 $(P<0.05)$ and p-ERK1/2 $(P<0.0001)$ levels compared with the control group (Figure 2). Despite the treatment with either PJ or PSE reduced t-ERK1/2 level in the lung tissue, the decrease was not significant $(P>0.05)$ as compared with the PQ (alone)treated group. On the other hand, PJ and PSE administration declined substantially the p-ERK1/2 level in the lung tissue $(P<0.001)$ when compared with the PQ (alone)-treated animals (Figure 2). 
(a)

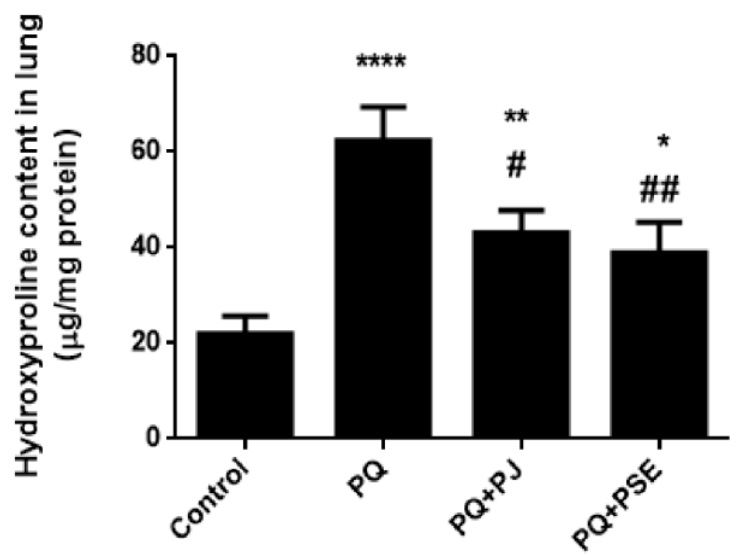

(c)

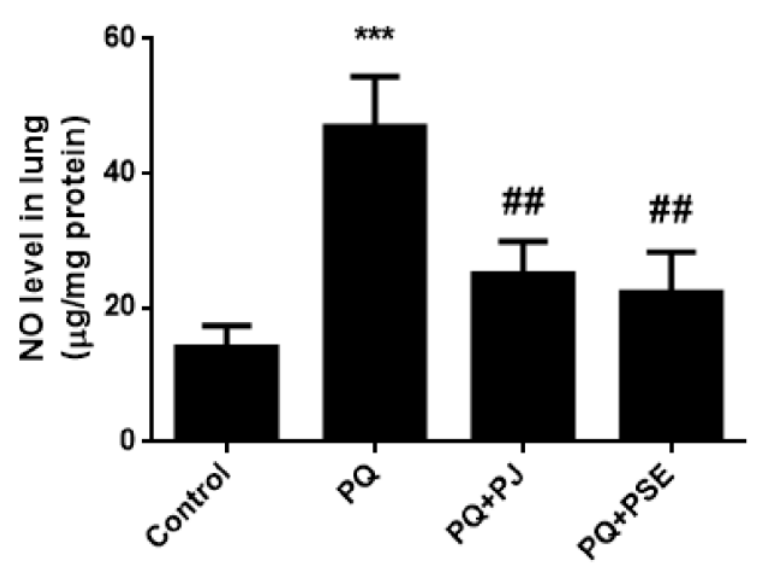

(b)

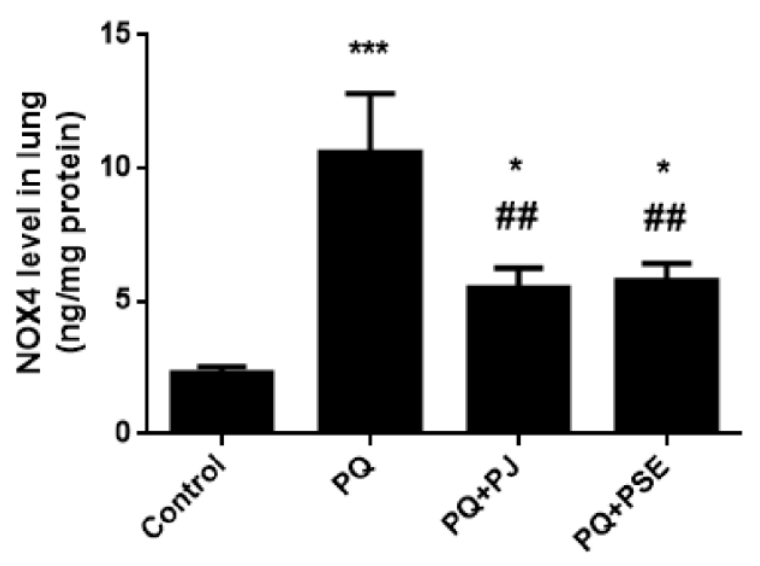

(d)

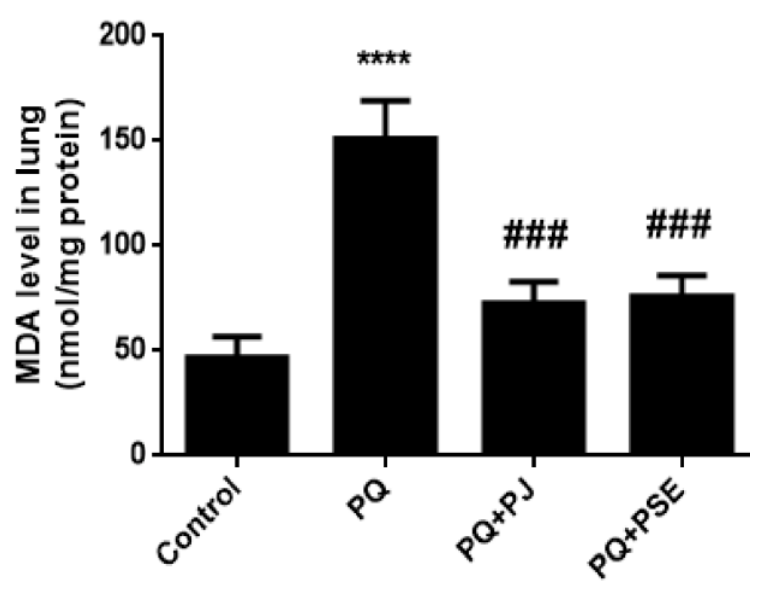

Figure 1: Effect of PJ and PSE pretreatment on hydroxyproline, NADPH oxidase 4 (NOX4), nitric oxide (NO), and malondialdehyde (MDA) levels in lung tissue of PQ-treated mice. Hydroxyproline (a), NOX4 (b), NO (c), and MDA (d) contents in lung tissue. PQ: paraquat group, $\mathrm{PQ}+\mathrm{PJ}$ : paraquat + pomegranate juice group, $\mathrm{PQ}+\mathrm{PSE}$ : paraquat + pomegranate seed extract group. Data were expressed as mean \pm standard deviation, $\mathrm{n}=8$. *: $P<0.05, * *: P<0.01$, ***: $P<0.001$, and ****: $P<0.0001$ compared with the control group; \#: $P<0.05$, \#\#: $P<0.01$, and \#\#\#: $P<0.001$ compared with the PQ-treated group.

Effects of PJ and PSE administration on the cytokine and chemokine levels in the lung tissue of the PQ-treated mice

The pulmonary levels of TGF- $\beta 1$, IL-6, IL-17, and CCL2 elevated significantly $(P<0.001-P<0.0001)$ in the PQ (alone)treated group when compared with the control animals (Figure 3). By administration of PJ prior to PQ injection, the levels of the lung TGF- $\beta 1$, IL-6, IL-17, and CCL2 substantially reduced $(P<0.01-P<0.0001)$ when compared with their levels in the
PQ (alone)-treated group. Moreover, PSE supplementation led to a remarkable decline in the above-mentioned cytokines and chemokine levels $(P<0.05-P<0.0001)$ as compared to the PQ (alone)-treated group (Figure 3).

\section{DISCUSSION}

The herbicide, PQ was reported to exhibit an elevated toxic impact on pulmonary tissues with the attributed mortality rate in human due to lung fibrosis ${ }^{[29]}$. Hydroxyproline 
content elevated significantly in the current study following PQ injection. Our findings were in line with Pourgholamhossein et $a l .{ }^{[30]}$, since hydroxyproline has been used as an indicator for the amount of collagen deposited in the lung tissue and pulmonary fibrosis. Both PJ and PSE treatment successfully reduced the augmented level of hydroxyproline in PQ-treated mice. PSE was previously proven to prevent lung fibrosis resulted from bleomycin injection ${ }^{[18]}$.

(a)

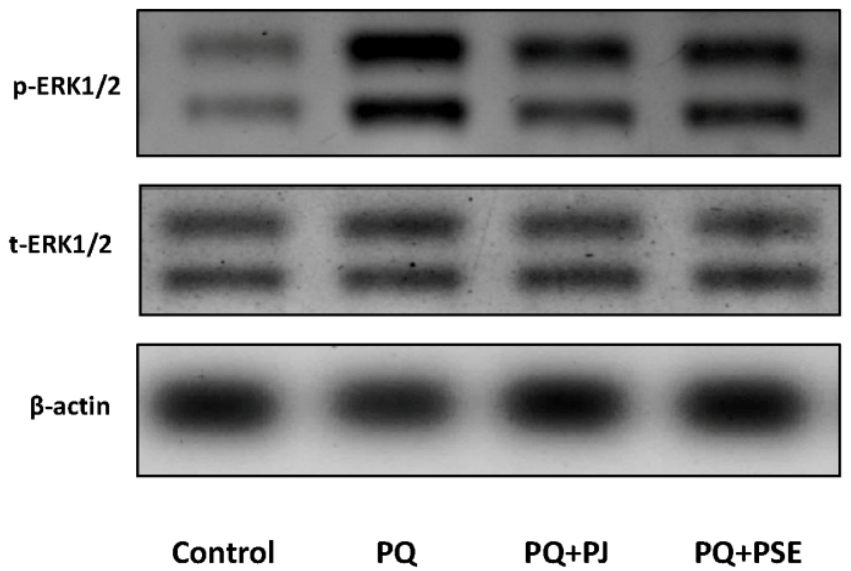

(b)

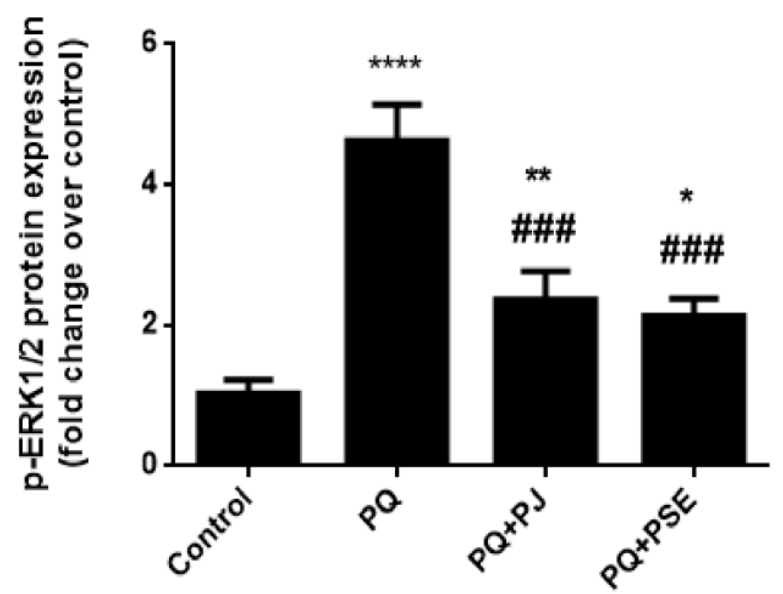

(c)

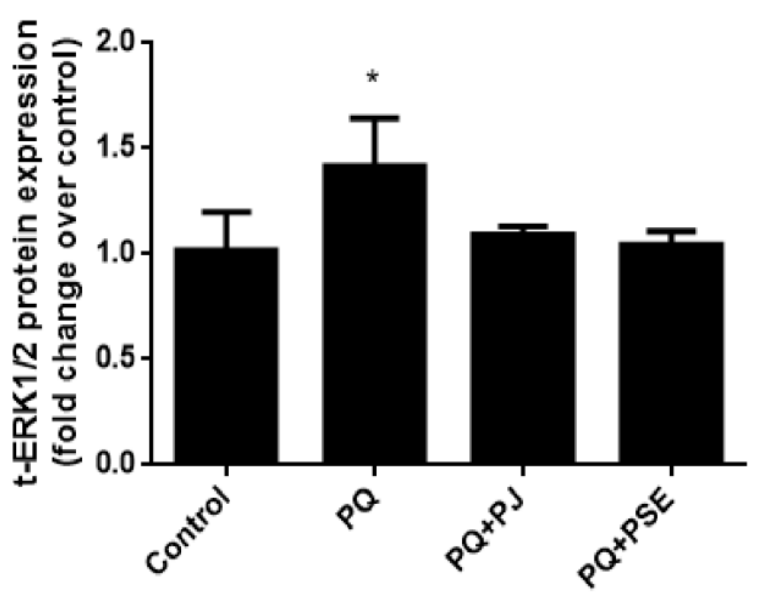

Figure 2: Effect of PJ and PSE pretreatment on pulmonary phosphorylated (p)-ERK1/2 and total (t)-ERK1/2 levels in in lung tissue of PQ-treated mice. (a) Western blot analysis, (b) p-ERK1/2 protein level, and (c) t-ERK1/2 protein level. ERK1/2: extracellular signalregulated kinase 1/2. $\mathrm{PQ}$ : paraquat group, $\mathrm{PQ}+\mathrm{PJ}$ : paraquat + pomegranate juice group, PQ+PSE: paraquat + pomegranate seed extract group. Data were expressed as mean \pm standard deviation, $\mathrm{n}=8$. *: $P<0.05$, **: $P<0.01$, and ****: $P<0.0001$ compared with the control group; \#\#\#: $P<0.001$ compared with the PQ-treated group.

The current study showed that NOX4 and NO were also induced upon PQ injection while PJ and PSE administration managed to restore their levels nearly towards the normal values. Accumulating evidence verified the idea of the induced
NOX4 expression in lung fibrosis ${ }^{[31,32]}$. It has been reported that NOXs are flavoenzymes that are responsible for initial formation of $\operatorname{ROS}^{[33]}$. Among the main proposed reasons behind PQ-triggered ROS release was the activation of NOXs, 
especially NOX4, in the inflammatory and pulmonary target tissues ${ }^{[31,34]}$. It has been reported that one of the significant inflammatory factor is NO, which is produced by inducible nitric oxide synthase and it is associated with induced inflammation. Increased production of $\mathrm{NO}$

(a)

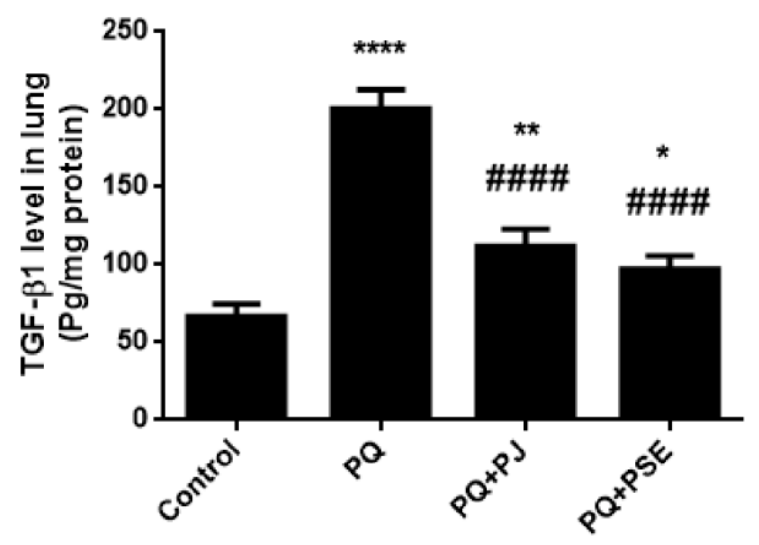

(c)

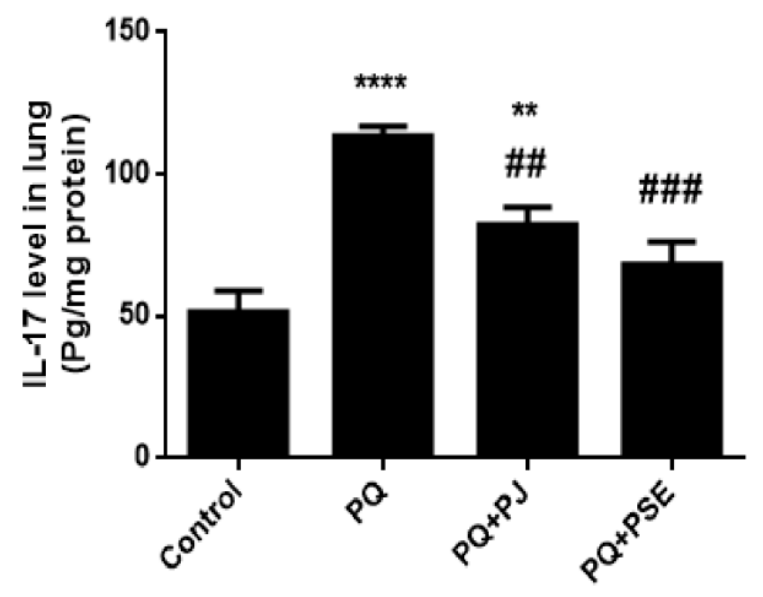

was established to cause cytotoxicity, inflammation, carcinogenicity, and autoimmune disorders ${ }^{[35,36]}$. Ethanol extract of pomegranate flower (PFE) was recorded to reduce the NO production in lipopolysaccharide (LPS)-activated RAW264.7 macrophages $^{[36]}$. (b)

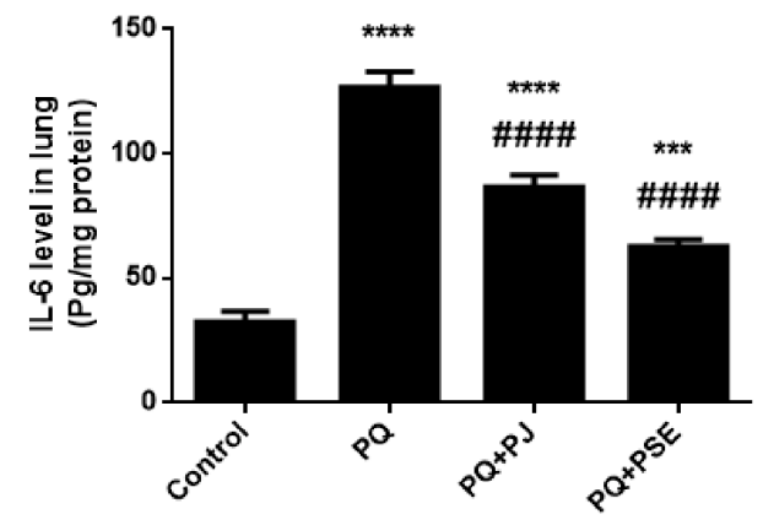

(d)

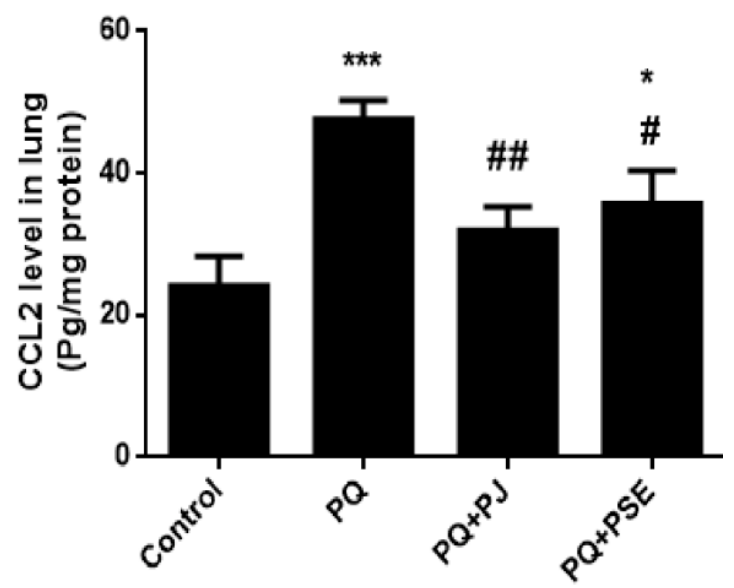

Figure 3: Effect of PJ and PSE administration on the cytokine and chemokine levels in the lung tissue of the PQ-treated mice. (a) TGF- $\beta 1$, (b) IL-6, (c) IL-17, and (d) CCL2 levels in lung tissue. TGF: transforming growth factor, IL: interleukin, CCL2: CC chemokine ligand 2, PQ: paraquat group, $\mathrm{PQ}+\mathrm{PJ}$ : paraquat + pomegranate juice group, $\mathrm{PQ}+\mathrm{PSE}$ : paraquat + pomegranate seed extract group. Data were expressed as mean \pm standard deviation, $\mathrm{n}=8$. *: $P<0.05, * *: P<0.01$, ***: $P<0.001$, and ****: $P<0.0001$ compared with the control group; \#: $P<0.05$, \#\#: $P<0.01$, \#\#\#: $P<0.001$, and \#\#\#\#: $P<0.0001$ compared with the PQ-treated group.

MDA is a crucial indicator of tissue injury due to oxidative stress. In this article, PQ injection led to oxidative stress as evidenced by elevated MDA level. PJ or PSE treatment improved the provoked pulmonary oxidative stress by $\mathrm{PQ}$ as 
indicated by reducing the MDA level. Previous study reported the importance of decreasing ROS production and oxidative stress in mediating the antifibrotic mechanisms ${ }^{[30]}$. In addition, lung oxidative injury was alleviated by pomegranate peel methanolic extract in methotrexate-treated rats ${ }^{[21]}$. Moreover, the protective effect of PSE was confirmed in bleomycin-triggered pulmonary fibrosis in rats due to its antioxidative properties ${ }^{[18]}$.

It was documented that the etiology for lung fibrosis was ascribed with inflammation and that various cytokine secretions were associated with induced pulmonary injury ${ }^{[29]}$. The present study revealed that the levels of CCL2, IL-6, TGF- $\beta 1$, and IL-17 elevated significantly following PQ treatment. The current experiment also showed an increase in the level of $p$-ERK1/2 following PQ injection in the lung tissue of mice. It was confirmed that IL-6 secretion from synovial fibroblasts was induced by CCL2 ${ }^{[14]}$. Accumulating evidence exhibited an increased IL-6 release in the lung of people with fibrotic pulmonary damage that may suggest its profibrogenic contribution $^{[37-39]}$ through the suppression of fibroblast apoptosis. Subsequently, CCL2 could be referred to as a profibrotic chemokine by triggering IL- 6 secretion. The underlying mechanism for the release of IL- 6 through CCL2 by human pulmonary fibroblast was attributed to the ERK1/2 signaling pathway that mediates CCL2 activation of IL-6 secretion ${ }^{[13]}$. CCL2 exhibits its effect via its $\mathrm{G}$ protein-coupled seven transmembrane spanning receptor "CCR2" that transmit the signal through $\mathrm{G}$ protein-coupled receptors, especially $\mathrm{Gi}$, which consequently triggers ERK $1 / 2$ signal pathway $^{[40]}$. TGF- $\beta 1$ is one of the inflammatory cytokines that also increased upon PQ treatment. It is well established that IL-6 and TGF- $\beta 1$ are among the inflammatory cytokines that were associated with the propagation of lung fibrosis ${ }^{[15,29]}$. TGF- $\beta 1$ is the prototype of a family of secreted growth factors with the varied ability of cell modulating processes such as apoptosis, cell migration, differentiation, and extracellular matrix secretion $^{[15,41]}$. Two signaling pathways were proved to control the release of TGF- $\beta 1$; Smad and non-Smad pathways. ERK1/2 belongs to a non-Smad pathway of TGF- $\beta 1$ signaling ${ }^{[15]}$. The proinflammatory cytokine, IL-17 was verified to enhance epithelial-mesenchymal transition (EMT) with subsequent induction of lung fibrosis ${ }^{[42]}$. It has been reported that IL-17 and CCL2 were crucial factors for fibrosis propagation in many organs in the body ${ }^{[13,42]}$. It was recorded that IL-17-induced EMT in lung epithelium may be due to TGF- $\beta 1$ activation and ERK1/2 associated signaling pathway ${ }^{[42]}$. Subsequently, PJ and PSE anti-inflammatory and anti-fibrotic effects may be attributed to the suppressed phosphorylation degree of ERK1/2. The anti-inflammatory effect of PFE pretreatment was shown to be associated with reduced phosphorylation of ERK in LPS-induced RAW264.7 macrophages ${ }^{[36]}$. In conclusion, it can be inferred from the current study that the protective effect of PJ and PSE against PQ-induced pulmonary fibrosis might be achieved through modulation of oxidative stress, inflammation, and the inhibition of the associated ERK1/2 phosphorylation.

\section{ACKNOWLEDGMENTS}

The authors thank Dr. Mohammed Salah Mahmoud Mohammed (Zoology Department, Faculty of Science, Fayoum University) for his technical support. This research received no funds.

\section{CONFLICT OF INTEREST}

The authors have no potential financial conflict of interest.

\section{REFERENCES}

[1] Javad-Mousavi, S. A.; Hemmati, A. A.; Mehrzadi, S. et al. (2016). Protective effect of Berberis vulgaris fruit extract against paraquat-induced pulmonary fibrosis in rats. Biomed Pharmacother, 81: 329-336. 
[2] Zyoud, S. E. (2018). Investigating global trends in paraquat intoxication research from 1962 to 2015 using bibliometric analysis. Am J Ind Med, 61(6): 462-470.

[3] Fukuda, Y.; Ferrans, V. J.; Schoenberger, C. I. et al. (1985). Patterns of pulmonary structural remodeling after experimental paraquat toxicity. The morphogenesis of intraalveolar fibrosis. Am J Pathol, 118(3): 452-475.

[4] Dinis-Oliveira, R. J.; Sarmento, A.; Reis, P. et al. (2006). Acute paraquat poisoning: report of a survival case following intake of a potential lethal dose. Pediatr Emerg Care, 22(7): 537540.

[5] Eddleston, M.; Wilks, M. and Buckley, N. (2003). Prospects for treatment of paraquat-induced lung fibrosis with immunosuppressive drugs and the need for better prediction of outcome: a systematic review. QJM, 96(11): 809-824.

[6] Shinozaki, S.; Kobayashi, T.; Kubo, K. et al. (1992). Pulmonary hemodynamics and lung function during chronic paraquat poisoning in sheep. Possible role of reactive oxygen species. Am Rev Respir Dis, 146(3): 775-780.

[7] Ahmed, A. A. E. (2009). Protective effect of montelukast on paraquatinduced lung toxicity in rats. Biosci Trends, 3(2): 63-72.

[8] Mainwaring, G.; Lim, F. L.; Antrobus, K. et al. (2006). Identification of early molecular pathways affected by paraquat in rat lung. Toxicology, 225(2-3): 157-172.

[9] Franco, R.; Sánchez-Olea, R.; Reyes-Reyes, E. M. et al. (2009). Environmental toxicity, oxidative stress and apoptosis: ménage à trois. Mutat Res, 674(1-2): 3-22.

[10] Adachi, J. (2000). "Membrane disorder and free radical". Nihon Hoigaku Zasshi, 54(3): 356-360.
[11] Orito, K., Suzuki, Y.; Matsuda, H. et al. (2004). Chymase is activated in the pulmonary inflammation and fibrosis induced by paraquat in hamsters. Tohoku J Exp Med, 203: 287-294.

[12] Mollace, V.; Muscoli, C.; Masini E. et al. (2005). Modulation of prostaglandin biosynthesis by nitric oxide and nitric oxide donors. Pharmacol Rev, 57(2): 217-252.

[13] Liu, X.; Das, A. M.; Seideman, J. et al. (2007). The CC chemokine ligand 2 (CCL2) mediates fibroblast survival through IL-6. Am J Respir Cell Mol Biol, 37(1): 121-128.

[14] Nanki, T.; Nagasaka, K.; Hayashida, K. et al. (2001). Chemokines regulate IL-6 and IL-8 production by fibroblast-like synoviocytes from patients with rheumatoid arthritis. J Immunol, 167(9): 5381-5385.

[15] Choe, J.-Y.; Jung, H.-J.; Park, K.-Y. et al. (2010). Anti-fibrotic effect of thalidomide through inhibiting TGF- $\beta$-induced ERK1/2 pathways in bleomycin-induced lung fibrosis in mice. Inflamm Res, 59(3): 177-188.

[16] El-Hashim, A. Z.; Khajah, M. A.; Renno, W. M. et al. (2017). Src-dependent EGFR transactivation regulates lung inflammation via downstream signaling involving ERK1/2, PI3K $\delta / A k t$ and NFKB induction in a murine asthma model. Sci Rep, 7(1): 9919 (DOI: 10.1038/ s41598-017-09349-0).

[17] Seeram, N. P.; Adams, L. S.; Henning, S. M. et al. (2005). In vitro antiproliferative, apoptotic and antioxidant activities of punicalagin, ellagic acid and a total pomegranate tannin extract are enhanced in combination with other polyphenols as found in pomegranate juice. J Nutr Biochem, 16(6): 360-367.

[18] Hemmati, A. A.; Rezaie, A. and Darabpour, P. (2013). Preventive 
effects of pomegranate seed extract on bleomycin-induced pulmonary fibrosis in rat. Jundishapur $\mathbf{J}$ Nat Prod, 8(2): 76-80.

[19] Singh, R. P.; Chidambara Murthy, K. N. and Jayaprakasha, G. K. (2002). Studies on the antioxidant activity of pomegranate (Punica granatum) peel and seed extracts using in vitro models. J Agric Food Chem, 50(1): 81-86.

[20] González-Molina, E.; Moreno, D. A. and García-Viguera, C. (2009). A new drink rich in healthy bioactives combining lemon and pomegranate juices. Food Chem, 115(4): 13641372.

[21] Doostan, F.; Vafafar, R.; ZakeriMilani, P. et al. (2017). Effects of pomegranate (Punica granatum L.) seed and peel methanolic extracts on oxidative stress and lipid profile changes induced by methotrexate in rats. Adv Pharm Bull, 7(2): 269-274.

[22] Husari, A.; Khayat, A.; Bitar, H. et al. (2014). Antioxidant activity of pomegranate juice reduces acute lung injury secondary to hyperoxia in an animal model. BMC Res Notes, 7: 664 (DOI: 10.1186/1756-0500-7-664).

[23] Qian, J.; Ye, Y.; Lv, L. et al. (2014). FTY720 attenuates paraquat-induced lung injury in mice. Int Immunopharmacol, 21(2): 426-431.

[24] Hartman, R. E.; Shah, A.; Fagan, A. M. et al. (2006). Pomegranate juice decreases amyloid load and improves behavior in a mouse model of Alzheimer's disease. Neurobiol Dis, 24(3): 506-515.

[25] Nunes-Souza, V.; Alenina, N.; Qadri, F. et al. (2016). CD36/sirtuin 1 axis impairment contributes to hepatic steatosis in ACE2-deficient mice. Oxid Med Cell Longev, 2016: 6487509 (DOI: 10.1155/2016/6487509).

[26] Bradford, M. M. (1976). A rapid and sensitive method for the quantitation of microgram quantities of protein utilizing the principle of protein-dye binding. Anal Biochem, 72: 248-254.

[27] Al-Fawaeir, S.; Özgür Akgül, E.; Çayc1, T. et al. (2011). Comparison of two methods for malondialdehyde measurement. J Clin Anal Med, 2(2): 11-14.

[28] Schulz, K.; Kerber, S. and Kelm, M. (1999). Reevaluation of the Griess method for determining $\mathrm{NO} / \mathrm{NO}_{2}^{-}$ in aqueous and protein-containing samples. Nitric Oxide, 3(3): 225-234.

[29] Chen, J.; Si, L.; Zhou, L. et al. (2019). Role of bone marrow mesenchymal stem cells in the development of PQ-induced pulmonary fibrosis. Mol Med Rep, 19(4): 3283-3290.

[30] Pourgholamhossein, F.; Rasooli, R.; Pournamdari, M. et al. (2018). Pirfenidone protects against paraquatinduced lung injury and fibrosis in mice by modulation of inflammation, oxidative stress, and gene expression. Food Chem Toxicol, 112: 39-46.

[31] Ghatak, S.; Hascall, V. C.; Markwald, R. R. et al. (2017). Transforming growth factor $\beta 1$ (TGF $\beta 1$ )-induced $\mathrm{CD}_{44}$ V6-NOX 4 signaling in pathogenesis of idiopathic pulmonary fibrosis. J Biol Chem, 292(25): 1049010519.

[32] Hecker, L.; Logsdon, N. J.; Kurundkar, D. et al. (2014). Reversal of persistent fibrosis in aging by targeting Nox4-Nrf2 redox imbalance. Sci Transl Med, 6(231): 231ra47 (DOI: 10.1126/scitranslmed.3008182).

[33] Teixeira, G.; Szyndralewiez, C.; Molango, S. et al. (2017). Therapeutic potential of NADPH oxidase 1/4 inhibitors. Br J Pharmacol 174(12): 1647-1669.

[34] Wang, X.; Luo, F.; Zhao, H. (2014). Paraquat-induced reactive oxygen species inhibit neutrophil apoptosis via a $\mathrm{p} 38$ MAPK/NF- $\kappa \mathrm{B}-\mathrm{IL}-6 / \mathrm{TNF}-\alpha$ positive-feedback circuit. PLoS One, 9(4): e93837 (DOI: 10.1371/journal. pone.0093837). 
[35] Lee, M.-Y.; Park, B.-Y.; Kwon, O.-K. et al. (2009). Anti-inflammatory activity of (-)-aptosimon isolated from Daphne genkwa in RAW264. 7 cells. Int Immunopharmacol, 9(7-8): 878885.

[36] Xu, J.; Zhao, Y. and Aisa, H. A. (2017). Anti-inflammatory effect of pomegranate flower in lipopolysaccharide (LPS)-stimulated RAW264.7 macrophages. Pharm Biol, 55(1): 2095-2101.

[37] Moodley, Y. P.; Misso, N. L. A.; Scaffidi, A. K. et al. (2003). Inverse effects of interleukin- 6 on apoptosis of fibroblasts from pulmonary fibrosis and normal lungs. Am J Respir Cell Mol Biol, 29(4): 490-498.

[38] Tabata, C.; Kubo, H.; Tabata, R. et al. (2006). All-trans retinoic acid modulates radiation-induced proliferation of lung fibroblasts via IL-6/IL-6R system. Am J Physiol Lung Cell Mol Physiol, 290(3): L597L606.
[39] Gomes, I.; Mathur, S. K.; Espenshade, B. M. et al. (2005). Eosinophilfibroblast interactions induce fibroblast IL-6 secretion and extracellular matrix gene expression: implications in fibrogenesis. J Allergy Clin Immunol, 116(4): 796-804.

[40] Jimenez-Sainz, M. C.; Fast, B.; Mayor, F. (Jr.) et al. (2003). Signaling pathways for monocyte chemoattractant protein 1-mediated extracellular signal-regulated kinase activation. Mol Pharmacol, 64(3): 773782.

[41] Derynck, R. and Akhurst, R. J. (2007). Differentiation plasticity regulated by TGF-beta family proteins in development and disease. Nat Cell Biol, 9(9): 1000-1004.

[42] Wang, T.; Liu, Y.; Zou, J.-F. et al. (2017). Interleukin-17 induces human alveolar epithelial to mesenchymal cell transition via the TGF- $\beta 1$ mediated Smad2/3 and ERK1/2 activation. PLoS One, 12(9): e0183972 (DOI: 10.1371/ journal.pone.0183972).

\section{How to cite this article:}

Fathy, S. M.; El-Dash, H. A. and Said, N. I. (2021). Effects of juice and seed extract of pomegranate on oxidative stress, inflammation, and phosphorylation of ERK1/2 in paraquat-induced acute lung injury in mice. Egyptian Journal of Zoology, 75: 48-59 (DOI: 10.12816/ejz.2021.55441.1048). 


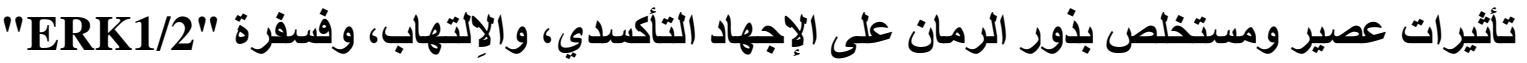 في الإصابات الرئوية الحادة المُستحثُة بالبار اكوات والات في الفئران وفئرة
}

\author{
سماح ممدوح محمد فتحي، هبه أحمد الاش، نهى إبراهيم سعيد سالم \\ قسم علم الحيوان، كلية العلوم، جامعة الفيوم، الفيوم، جمهورية مصر العربية
}

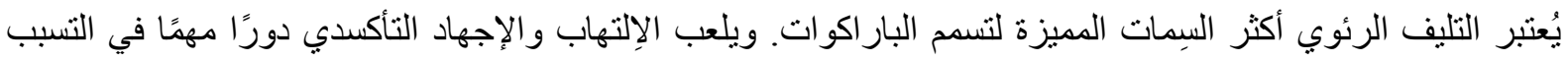

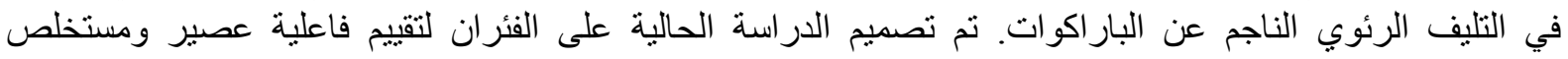

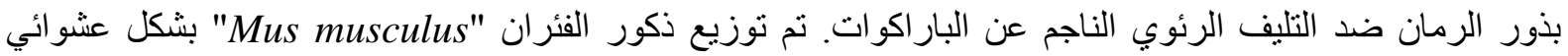

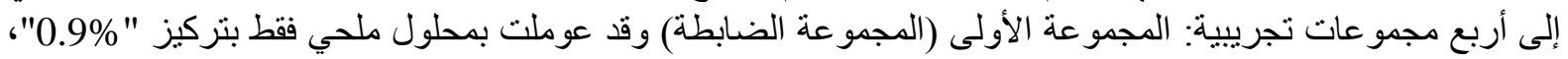

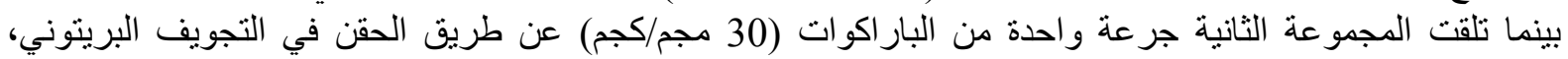

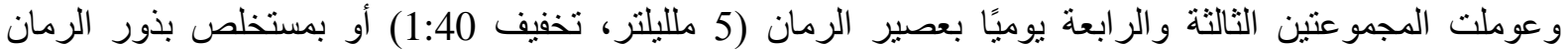

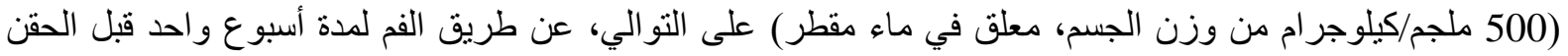

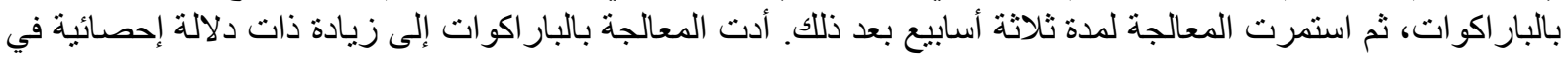

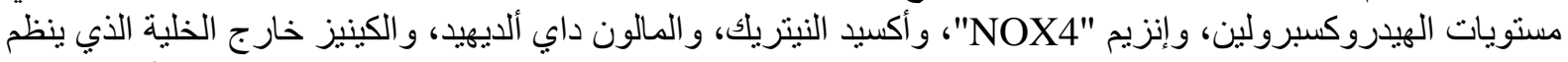

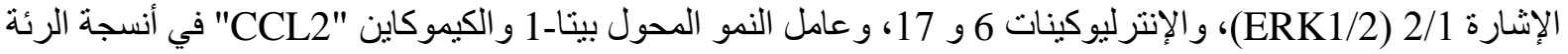

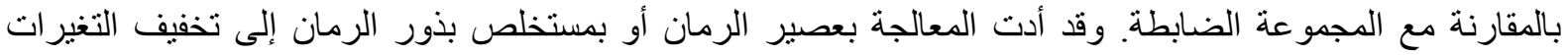

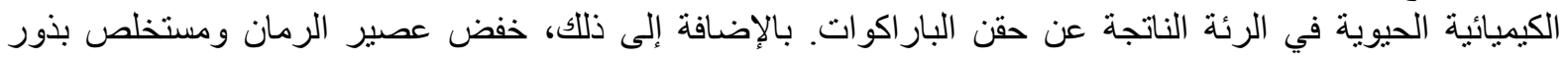

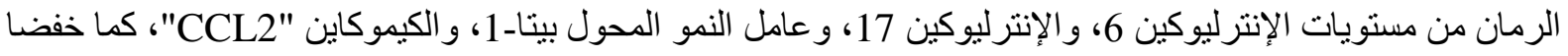

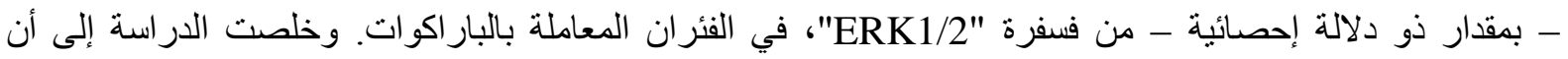

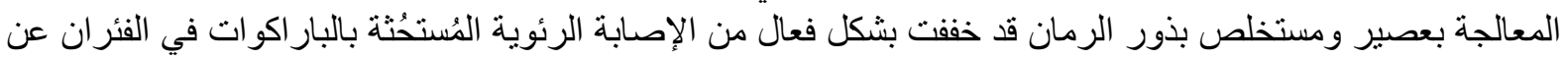
طريق تخفيف الإِلتهاب، و الإجهاد التأكسدي، و التليف. 